\title{
Studies on Lithium-Ion Diffusion in Heat-Treated CNBs by Microelectrode Method
}

\section{$\operatorname{AUTHOR}(\mathrm{S})$ :}

Sano, Atsushi; Kurihara, Masato; Abe, Takeshi; Ogumi, Zempachi

\section{CITATION:}

Sano, Atsushi ...[et al]. Studies on Lithium-lon Diffusion in Heat-Treated CNBs by

Microelectrode Method. Journal of The Electrochemical Society 2009, 156(8): A639-A644

\author{
ISSUE DATE: \\ 2009-05-26 \\ URL: \\ http://hdl.handle.net/2433/109926 \\ RIGHT: \\ (C) 2009 The Electrochemical Society
}




\title{
Studies on Lithium-Ion Diffusion in Heat-Treated CNBs by Microelectrode Method
}

\author{
Atsushi Sano, ${ }^{\mathrm{a}, *, \mathrm{z}}$ Masato Kurihara, ${ }^{\mathrm{a}, *}$ Takeshi Abe, ${ }^{\mathrm{b}, *}$ and Zempachi Ogumi ${ }^{\mathrm{b}, * *}$ \\ ${ }^{a}$ TDK Corporation, Device Development Center, Chiba 286-8588, Japan \\ ${ }^{b}$ Department of Energy and Hydrocarbon Chemistry, Graduate School of Engineering, Kyoto University, \\ Kyoto 615-8510, Japan
}

The ability of lithium-ion diffusion in carbon nanobeads (CNBs) was investigated by the microelectrode method [cyclic voltammetry, constant current charge/discharge, potential step, and potentiostatic intermittent titration technique (PITT)]. CNBs showed high rate discharge capacities of over $1000 \mathrm{C}$. CNB heat-treated at 1000,1500 , and $2000^{\circ} \mathrm{C}$ showed a higher charge ability than $2800^{\circ} \mathrm{C}$. The lithium-ion diffusion coefficient $\left(D_{\mathrm{Li}^{+}}\right)$in CNBs was investigated by PITT. $D_{\mathrm{Li}^{+}}$was different in the intercalation and deintercalation directions in 1000,1200 , and $1500^{\circ} \mathrm{C}$ CNBs. $D_{\mathrm{Li}^{+}}$of the intercalation and the deintercalation showed different potential dependencies. The $1200^{\circ} \mathrm{C}$ heat-treated CNB showed the highest $D_{\mathrm{Li}^{+}}$in the direction of intercalation. (C) 2009 The Electrochemical Society. [DOI: 10.1149/1.3138724] All rights reserved.

Manuscript submitted February 23, 2009; revised manuscript received April 21, 2009. Published May 26, 2009.

Recently, high rate charge/discharge energy devices have attracted attention. The high rate lithium-ion battery is especially interesting for its application to the hybrid electric vehicles and power tools. This is because the lithium-ion battery has a higher voltage than other energy devices such as the electric double layer capacitor or the $\mathrm{Ni}-\mathrm{H}$ battery.

Graphite or nongraphitized carbon is used for the negative electrode of the lithium-ion battery. Lithium-ion intercalates to a carbon electrode during charging and deintercalates during discharging. The speed of intercalation and deintercalation determines the input power and output power of the negative electrode. Therefore, the diffusion of lithium ion in the carbon electrode is important to the design and cell performance. The diffusion coefficient $\left(D_{\mathrm{Li}^{+}}\right)$of lithium ion in a graphite negative electrode was investigated by potentiostatic intermittent titration (PITT), impedance spectroscopy, and cyclic voltammetry $(\mathrm{CV}) .{ }^{1-5}$ This value of $D_{\mathrm{Li}^{+}}$is $10^{-6}-10^{-10} \mathrm{~cm}^{2} \mathrm{~s}^{-1}$. Levi et al. concluded that the $D_{\mathrm{Li}^{+}}$does not depend on the thickness of the electrode but depends on the basal plane dimension for the particles. Funabiki et al. ${ }^{4,5}$ specified the surface area of the edge plane and basal planes by using highly oriented pyrolytic graphite. They investigated the lithium-ion diffusion and the phase boundary for different stages of graphite intercalated compounds by the method of potential step chronoamperometry (PSCA). Phase boundary movement was initially determined by the rate of reaction at the graphite/electrolyte interface and was thereafter determined by the diffusion of lithium ions in the graphite. Because small particles have shorter diffusion lengths than larger particles, small particles have an advantage in Li-ion diffusion into graphite.

Aurbach et al. reported on the diffusion coefficient of lithium ion in a graphite electrode by PITT and Warburg impedance. ${ }^{1,6,7}$ They also investigated the dependence on the graphite particle size. Their data suggest that as the graphite size becomes smaller, the diffusion coefficient of $\mathrm{Li}$ ion into the graphite becomes smaller. They explained this result in terms of an edge effect of the surface films partially covering the graphite particles.

Wang et al. investigated graphitized carbon nanobeads (GCNBs). GCNBs have an onionlike texture and a diameter of about $0.2 \mu \mathrm{m} .{ }^{8}$ By transmission electron microscope (TEM) imaging, they found that this uniquely shaped carbon does not aggregate like carbon blacks. Typical graphite cannot be used in propylene carbonate (PC) because the graphite layer exfoliates in PC-based electrolytes when the $\mathrm{Li}$ ion intercalates into graphite. But GCNBs showed reversible intercalation and deintercalation in PC-based electrolytes. The high

\footnotetext{
* Electrochemical Society Active Member

** Electrochemical Society Fellow.

z E-mail: sanoa@jp.tdk.com
}

rate discharge capacity was larger than mesocarbon microbeads (MCMBs). They concluded that this high rate performance was due to the short diffusion path of GCNBs and that the resistance of solid electrolyte interphase was very small.

We focused on carbon nanobeads (CNBs) for high rate charge and high rate discharge use. The electrochemical characteristics of CNB heat-treated from 1000 to $2800^{\circ} \mathrm{C}$ were investigated. In our investigation, we used the microelectrode method to measure $\mathrm{CV}$, constant current charge/discharge, PSCA, and PITT.

Single-particle electrochemical measurement was studied by Uchida et al. ${ }^{9-11}$ They used microsized single particles or secondary particles for $\mathrm{CV}$ or ac impedance measurement. In this study, we used the secondary particles of $\mathrm{CNB}$, which have dimensions of around $30 \mu \mathrm{m}$ for the secondary particle and $0.2 \mu \mathrm{m}$ for the primary particle. The microelectrode measure has some merit. Li-ion diffusion into an electrolyte is spherical diffusion; thus the Li-ion diffusion in an electrolyte is faster than that in the usual combined electrode. In the microelectrode method, a binder or an electroconductive material is not used. Therefore it is possible to evaluate the performance of the active material itself. By using these methods, we investigated the electrochemical characteristics of heat-treated CNBs.

\section{Experimental}

CNBs were prepared by chemical vapor deposition at Tokai Carbon Co. Ltd. The details of the preparation procedure were reported previously. ${ }^{8,12}$ The CNB were heat-treated in an electric oven under $\mathrm{Ar}$ atmosphere at $1200,1500,2000$, and $2800^{\circ} \mathrm{C}$. The temperature was maintained for $20 \mathrm{~h}$.

Microelectrode measurement.- A schematic view of the equipment is shown in Fig. 1. The cell formation was in a two-electrode cell. Heat-treated CNBs were used as the working electrodes. A $\mathrm{CNB}$ was composed of aggregations of $\mathrm{CNB}$ particles. The diameter of the aggregation was approximately $30 \mu \mathrm{m}$, which was selected for the measurement. MCMBs (Osaka gas) were also used as the active material of working electrodes. Special use stainless steel wire $(10 \mu \mathrm{m})$ covered with glass as an insulator was contacted with the working electrode for the current collection. The counter electrode was lithium metal. We determined that the Ohmic drop and the impedance of the counter electrode were low enough to evaluate the working electrode. $1 \mathrm{~mol} \mathrm{dm}{ }^{-3} \mathrm{LiPF}_{6}$ dissolved in ethylene carbonate:diethyl carbonate (3:7) (volume ratio) was used as the electrolyte. All electrochemical measurements were carried out in an $\mathrm{Ar}$ glove box (the dew point is below $-70^{\circ} \mathrm{C}$ ).

Electrochemical measurements were carried out by HZ3000 (Hokuto denko). CV, constant current charge/discharge, PSCA, and PITT were measured. CV was carried out at various sweep rates from 0.5 to $640 \mathrm{mV} / \mathrm{s}$. In the constant current charge/discharge measurements, the current was set between 10 and $2000 \mathrm{nA}$. The cutoff 


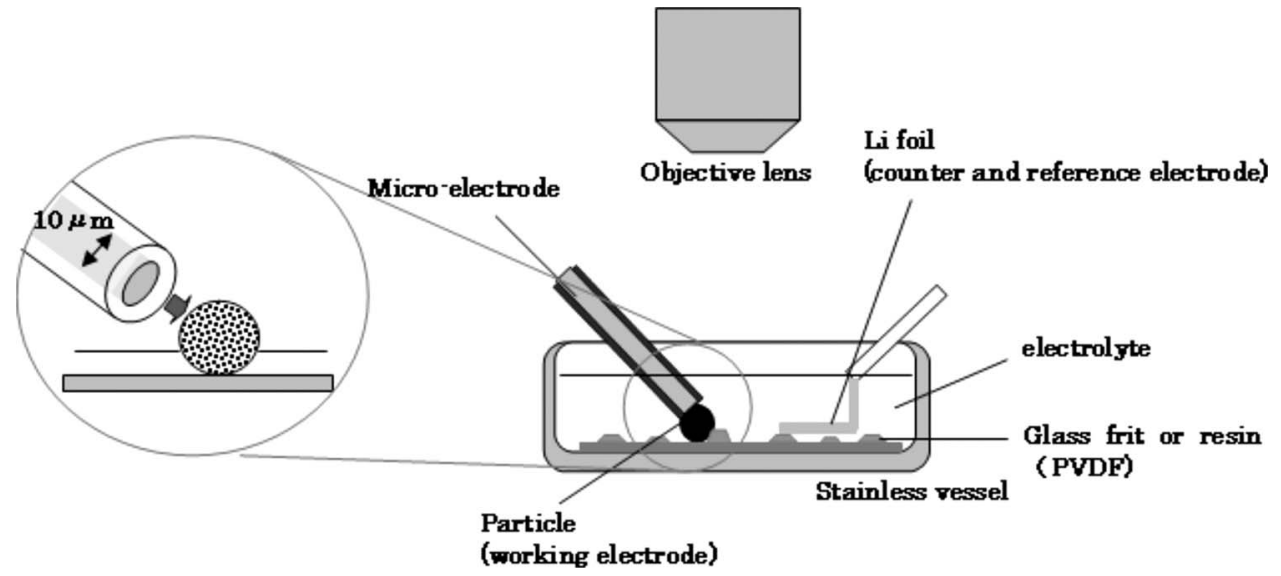

Figure 1. Schematic image of small electrode measurement equipment.

potential was 0-3.0 V vs $\mathrm{Li} / \mathrm{Li}^{+}$. TEM (JEM3010, JEOL) was used for the observation of the structure of CNBs. CNB samples were on a gold microgrid.

\section{Results}

The TEM images of heat-treated CNBs are shown in Fig. 2. A graphitized layer structure was not observed in the CNB heat-treated to $1000^{\circ} \mathrm{C}$. The $\mathrm{CNB}$ heated to $1200^{\circ} \mathrm{C}$ showed a slight concentric ring structure. A black dot and a wave form structure were observed for the $1500^{\circ} \mathrm{C}$ temperature. The black dot structure means strain in the structure. Thus the $1500^{\circ} \mathrm{C}$-heated $\mathrm{CNB}$ has a distorted layer structure in the circumferential direction. The $2000^{\circ} \mathrm{C}$-heated CNB formed a specific layered structure with a polyhedron face, which is a well-developed layer structure. The $2800^{\circ} \mathrm{C}$-heated $\mathrm{CNB}$ has more strain than the $2000^{\circ} \mathrm{C}$-heated one. It seems that each basal plane was pushed together and caused the strain. The inner part of the $2800^{\circ} \mathrm{C}$-heated CNB was a ribbonlike carbon. This suggests that the large strain at this heating temperature prevented the development of a graphite structure in the inner layer. The outermost layer for this $2800^{\circ} \mathrm{C}$-heated $\mathrm{CNB}$ was coated with amorphous-like carbon.

Figure 3 shows the optical microscope images of CNBs and MCMBs used in this experiment. The MCMB used in the measurement was a single particle. The sizes of the $\mathrm{CNB}$ and the MCMB were selected to be close both in capacity and in dimension.
CV was carried out in the microelectrode method (Fig. 4). In 1000 and $1200^{\circ} \mathrm{C}$ heat-treated CNBs, cathodic current peaks were observed at 0.20 and $0 \mathrm{~V}$ while anodic current peaks were observed at 0.25 and $1.0 \mathrm{~V}$. The cathodic peak at $0 \mathrm{~V}$ corresponds to the anodic peak at $0.25 \mathrm{~V}$, and the cathodic peak at $0.20 \mathrm{~V}$ corresponds to the anodic peak at $1.0 \mathrm{~V}$. These redox pairs show the lithium-ion intercalation to CNB and deintercalation. ${ }^{13-16}$ Dahn et al. ${ }^{13-15}$ and Tatsumi et al. ${ }^{16}$ reported that soft carbons heat-treated at low temperatures showed redox pairs at around $1.0 \mathrm{~V}$. In the $1500^{\circ} \mathrm{C}$ heattreated $\mathrm{CNB}$, a cathodic current peak was observed at $0.65 \mathrm{~V}$ and an anodic current peak was observed at $1.0 \mathrm{~V}$. In the $1500^{\circ} \mathrm{C}$ heattreated $\mathrm{CNB}$, the hysteresis is smaller than that in 1000 and $1200^{\circ} \mathrm{C}$ heat-treated CNBs. In the $2000^{\circ} \mathrm{C}$ heat-treated $\mathrm{CNB}$, one cathodic peak and one anodic peak were observed. The anodic peak was at $0.3 \mathrm{~V}$. At $2800^{\circ} \mathrm{C}$, the anodic peak was observed at $0.25 \mathrm{~V}$. The anodic peaks of the CNBs decreased as the temperature of heattreatment increased. The anodic peak of the MCMB was $0.42 \mathrm{~V}$, which is higher than that for the $2800^{\circ} \mathrm{C}$ heat-treated CNB. The intercalation/deintercalation of MCMB needs a larger overpotential than $\mathrm{CNB} 2800^{\circ} \mathrm{C}$. This result indicates that the lithium-ion diffusion in $\mathrm{CNB}$ is faster than in MCMB.

We investigated the relationship between the sweep rate $(0.5-$ $640 \mathrm{mV} / \mathrm{s}$ ) and the cathodic capacities integrated by the cathodic current (Fig. 5). Heat-treatment at 1000,1200 , or $1500^{\circ} \mathrm{C}$ did not

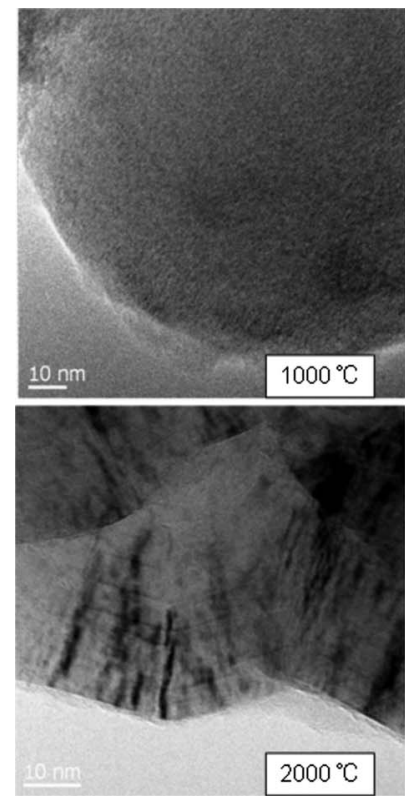

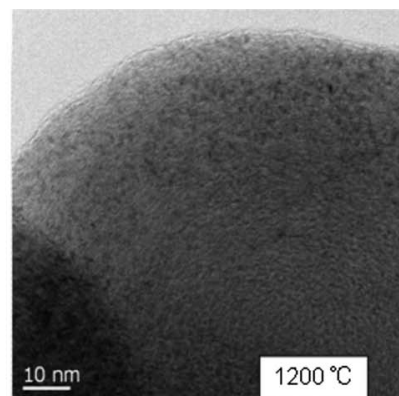

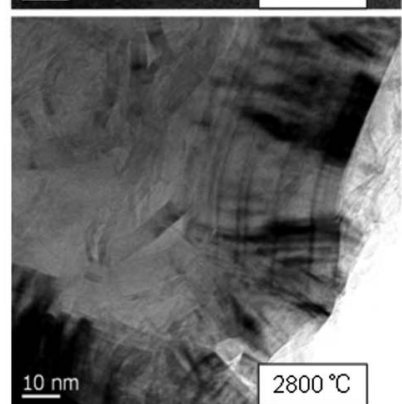

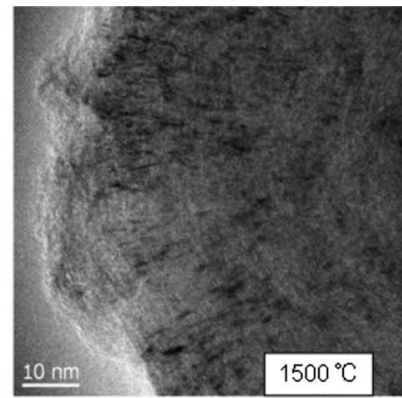

Figure 2. TEM images of heat-treated CNB. 

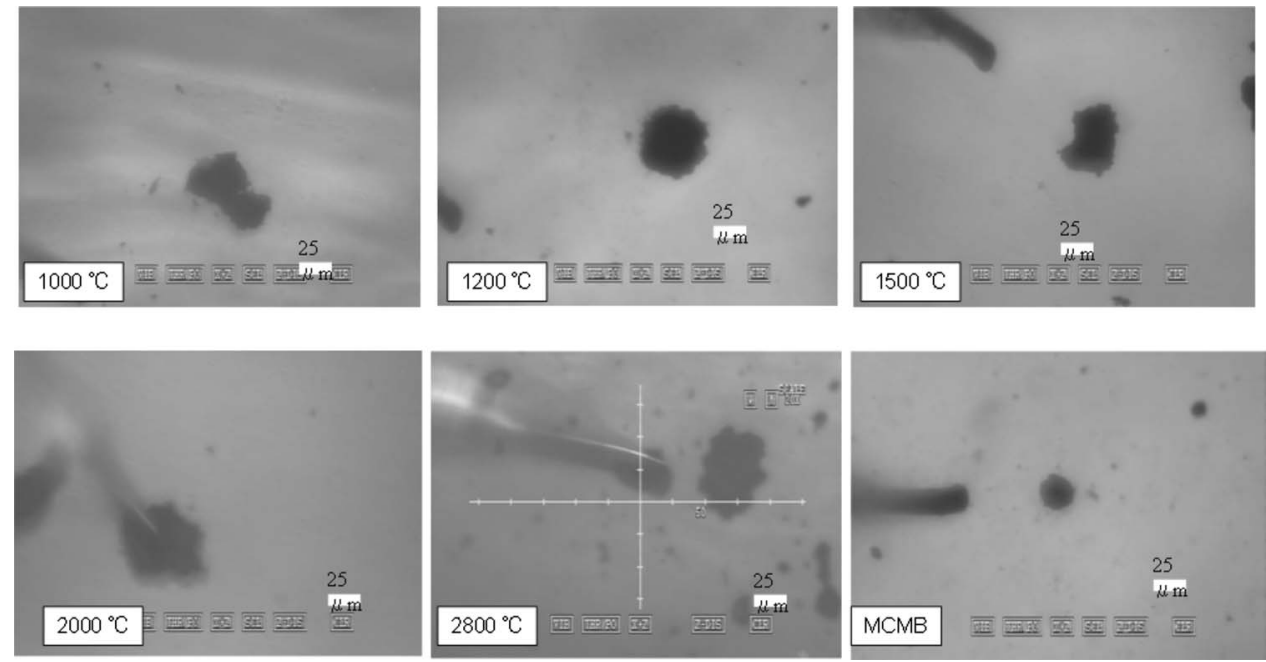

Figure 3. Optimal images of heat-treated CNB measured by small particle electrode method. make much difference. In the $2000^{\circ} \mathrm{C}$ heat-treated CNB, the capacity was slightly lower than that for the CNB heat-treated below $1500^{\circ} \mathrm{C}$. The capacity of the $2800^{\circ} \mathrm{C}$ heat-treated $\mathrm{CNB}$ was much lower than that for the $2000^{\circ} \mathrm{C}$ heat-treated CNB especially at the high rate. This is probably due to the ratio of the basal plane to the edge plane. The lithium ion intercalates from the edge plane only. The $2000^{\circ} \mathrm{C}$ heat-treated $\mathrm{CNB}$ should have more edge than the $2800^{\circ} \mathrm{C}$ one because the basal plane is not well developed in the $2000^{\circ} \mathrm{C}$ heat-treatment. More edge planes enable the rapid kinetic lithium-ion intercalation. The other mechanism that we propose is based on the structure of CNBs. The $2800^{\circ} \mathrm{C}$-heated CNB contains a larger distortion in the graphene sheet than the $2000^{\circ} \mathrm{C}$-heated one. This was observed by TEM. This distortion should interrupt the smooth lithium-ion intercalation.

We investigated the relationship between the sweep rate (1-640 $\mathrm{mV} / \mathrm{s}$ ) and the anodic capacities measured by CV. The tendency was similar to the cathodic capacities shown in Fig. 5. This result indicates that the capacity is determined by the cathodic sweep rate because the intercalation rate was slower than that of the deintercalation.
The constant current charge/discharge was carried out (Fig. 6). The 1000 and $1200{ }^{\circ} \mathrm{C}$ heat-treated CNBs show moderate curves between 0 and $3.0 \mathrm{~V}$. This behavior is observed in low temperature heat-treated soft carbons. ${ }^{13-16}$ The average charge/discharge potential decreased as the temperature of the heat-treatment of the CNB increased. These behaviors are similar to the electrochemical properties of petroleum cokes heat-treated at various temperatures. ${ }^{16}$ MCMBs showed different discharge curves compared with CNBs. MCMBs exhibit a large Ohmic drop followed by a flat potential. This result is most likely due to the difference in structure between CNBs and MCMBs.

The relationship between the discharge rate and the discharge capacity is shown in Fig. 7. All samples were able to discharge above the $1000 \mathrm{C}$ rate, which means fully discharged at $1 / 1000 \mathrm{~h}$. In the microelectrode method, lithium-ion diffusion into the electrolyte is spherical, which decreases the concentration polarization in the electrolyte and enables a rapid lithium-ion diffusion. The $1200^{\circ} \mathrm{C}$ heat-treated CNB showed the highest rate performance, and the $2000^{\circ} \mathrm{C}$ one was lowest. These results contain an Ohmic drop, an average potential, and a cutoff potential. Thus it is not easy to com-

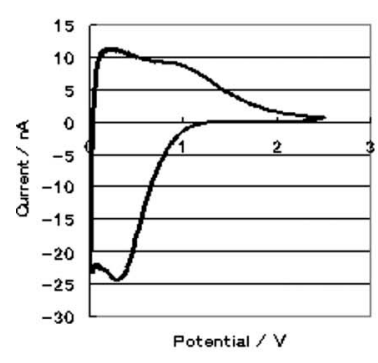

Withiout heat treat

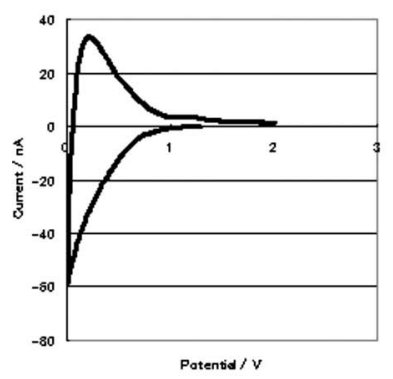

$2000^{\circ} \mathrm{C}$

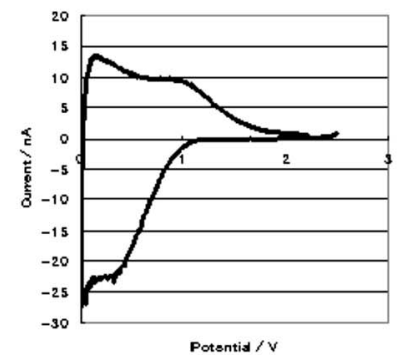

$1200^{\circ} \mathrm{C}$

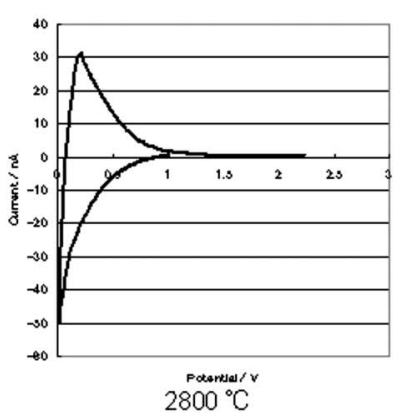

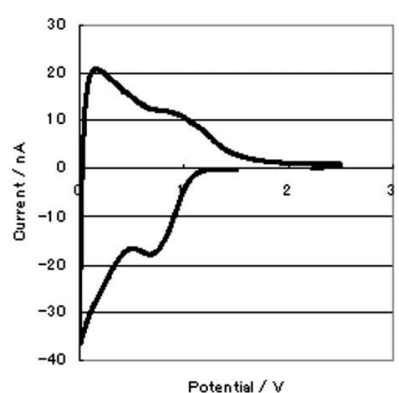

$1500^{\circ} \mathrm{C}$

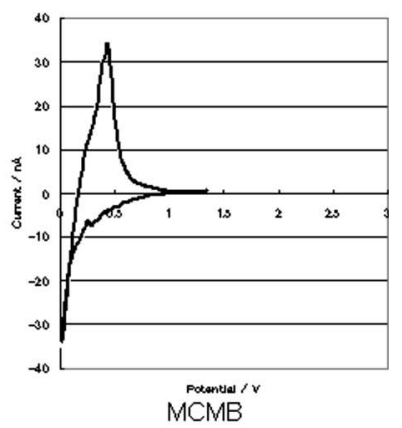

Figure 4. $\mathrm{CV}$ of heat-treated $\mathrm{CNB}$ after several cycles. Sweep rate: $5 \mathrm{mV} / \mathrm{s}$. 


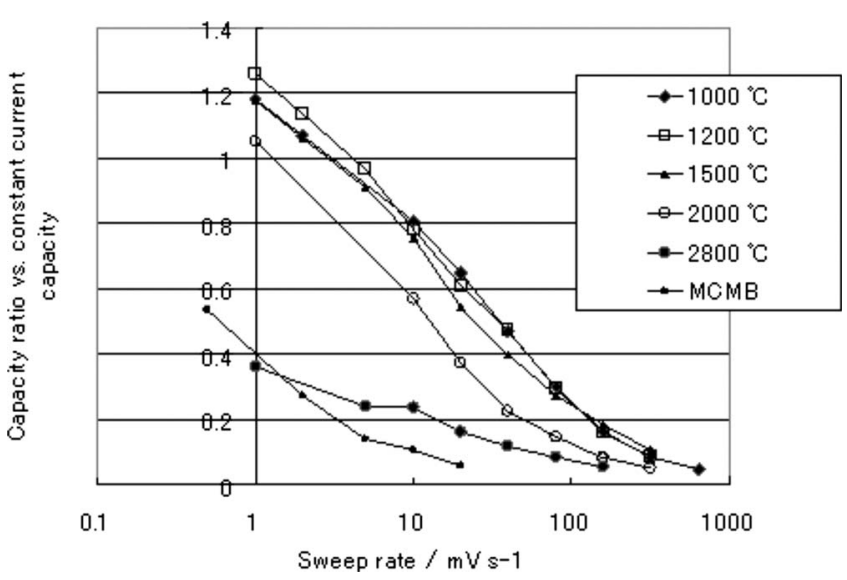

Figure 5. Relationship between sweep rate and cathodic capacity ratio vs constant current capacity

pare the discharge rate directly. However, it is obvious that CNBs showed a high rate performance for over $1000 \mathrm{C}$ discharge.

The discharge rate was measured by the potential step method (Fig. 8). The potential was stepped from 0.05 to $1.5 \mathrm{~V}$. The time after the potential was stepped, and the discharge capacity was measured. The $1200^{\circ} \mathrm{C}$ heat-treated CNB had the fastest discharge, with the discharge rate increasing in the following order: $1000 \fallingdotseq 2000$, 1500 , and $2800^{\circ} \mathrm{C}$ heat-treated CNB and MCMB. The 1200,1000 , and $2000^{\circ} \mathrm{C}$ heat-treated CNBs showed similar performances. The $1500^{\circ} \mathrm{C}$ was slightly slower than the 1200,1000 , and $2000^{\circ} \mathrm{C}$ heattreated CNB. The $2800^{\circ} \mathrm{C} \mathrm{CNB}$ was significantly slower than other temperatures. The potential gap between the average deintercalation potential and the set potential $(1.5 \mathrm{~V})$ is an important factor because the large potential gap is advantageous for a rapid discharge. The $2800^{\circ} \mathrm{C}$ heat-treated CNB has the largest potential gap among the CNBs. Nevertheless, the discharge rate for this $2800^{\circ} \mathrm{C}$ treatment was lowest. Based on these results, the lithium-ion diffusion in the $2800^{\circ} \mathrm{C} \mathrm{CNB}$ is slow, and it is due to the fewer diffusion paths observed by TEM images than for other CNBs. It is most likely attributed to the distortion of the basal plane. The discharge rate for the MCMB is much faster than that for the $2800^{\circ} \mathrm{C}$ heat-treated CNB. This is expected because of the lamellar structure of the MCMB.

Figure 9 shows the charge rate measured by the potential step method. The potential was stepped from the discharged open-circuit potential to $0.05 \mathrm{~V}$. The time and the charge capacity were measured. The charging rate followed the temperature of heat-treatment, $1000>1200>1500>2000>2800{ }^{\circ} \mathrm{C}>\mathrm{MCMB}$. This result

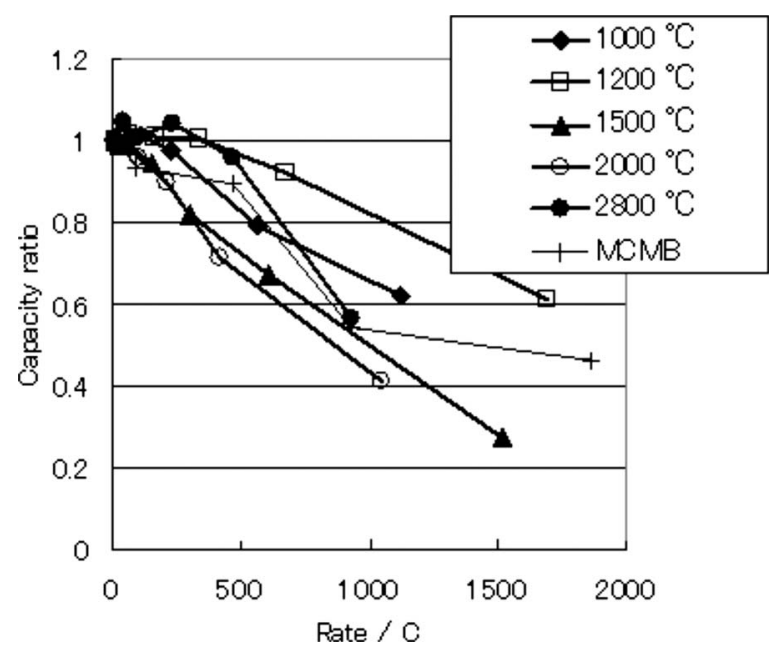

Figure 7. Ultrahigh rate discharge of heat-treated CNB.

reflects the specific structure of the $\mathrm{CNB}$ observed in the discharge rate performance and the effect of the potential gap between the intercalation potential and the set potential $(0.05 \mathrm{~V})$. The lower potential gap of the higher temperature CNB leads to a lower charge rate.

The discharge rate of the MCMB was much higher than that of the $2800^{\circ} \mathrm{C}$ heat-treated $\mathrm{CNB}$. However, the charge rate of the MCMB was much slower than that of the $2800^{\circ} \mathrm{C}$ heat-treated CNB. It is interesting to consider the mechanism of the high rate charge and discharge, which is attributed to the graphite structure.

The lithium-ion diffusion constant was investigated by the PITT method. Gnanaraj et al. ${ }^{17}$ and Wen et al. ${ }^{18}$ introduced $\log t$ and $I t^{1 / 2}$ plots to specify the Cotterell region time. The maximum value of $I t^{1 / 2}$ appears in the neighborhood of the characteristic diffusion time $\tau$. The maximum value of $I t^{1 / 2}$ moved to the left, which shows that lithium-ion diffusion is faster.

Figure 10 shows the potential dependence of the diffusion constant $\left(D_{\mathrm{Li}^{+}}\right) \cdot D_{\mathrm{Li}^{+}}$was calculated by the formula

$$
\begin{gathered}
\tau=\left(Q m \Delta X / \pi^{1 / 2} I t^{1 / 2}\right)^{2} \\
\tau=l^{2} / D_{\mathrm{Li}^{+}}
\end{gathered}
$$

where $Q m$ is the total capacity of the intercalation or deintercalation and $l$ is the diffusion length. Aurbach et al. assumed $l$ as the radius of the graphite particle. ${ }^{1,17}$ In this study, we took $l$ as the half of the particle size of CNB $(0.1 \mu \mathrm{m})$.
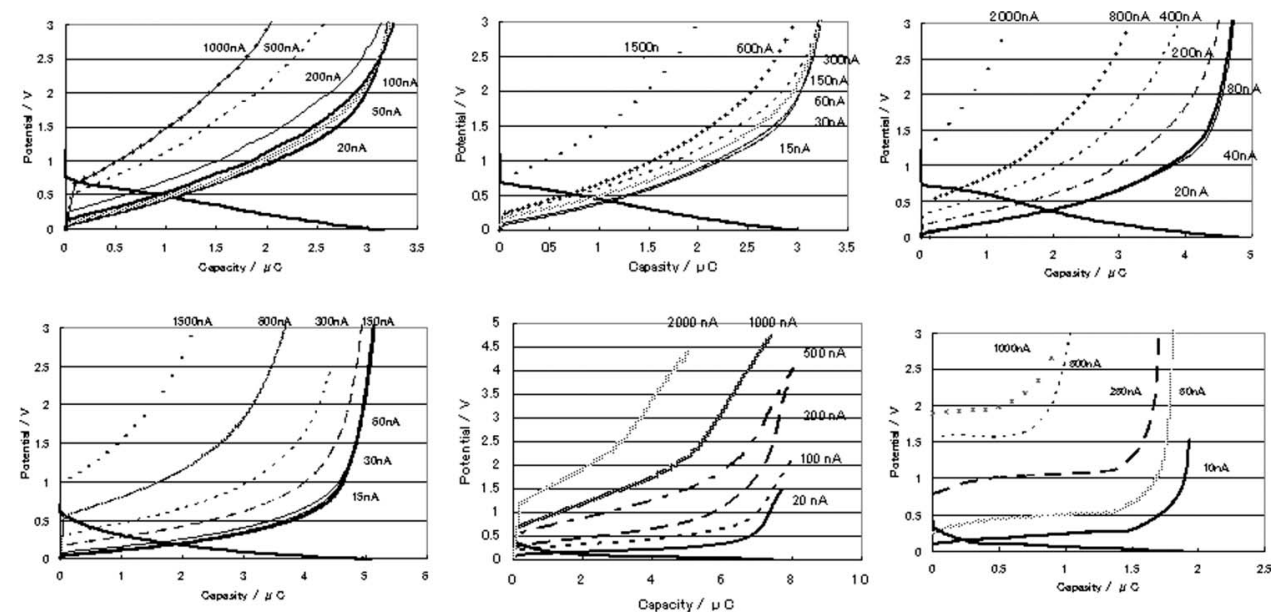

Figure 6. Charge and discharge curves of heat-treated $\mathrm{CNB}$ (constant current). 


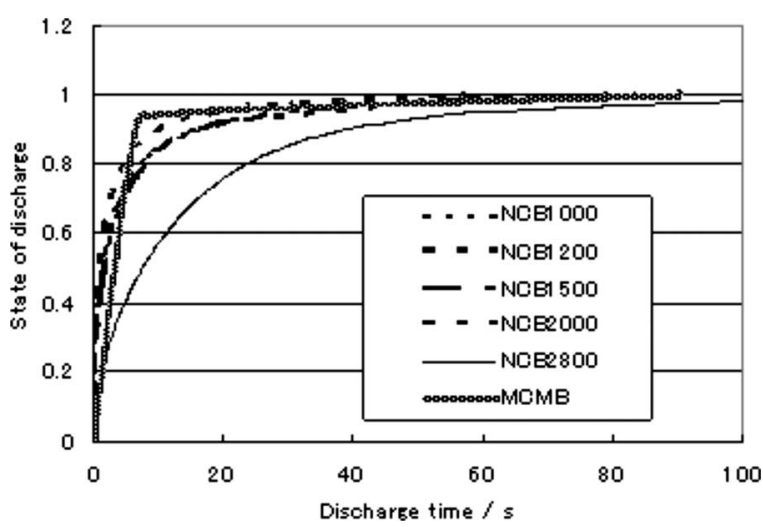

Figure 8. Relationship between potential step discharge time (from 0.05 to $1.5 \mathrm{~V})$ and state of discharge.

In the $2800^{\circ} \mathrm{C}$ heat-treated $\mathrm{CNB}, D_{\mathrm{L}^{+}}$increased as the potential increased. $D_{\mathrm{Li}^{+}}$was around $10^{-12}-10^{-11} \mathrm{~cm} / \mathrm{s}$. This value is lower than a reported value for graphite. ${ }^{1,17}$ It should be taken into account that CNB consists of aggregated particles, and diffusion into the core of the aggregated particle may control the diffusion rate. In that case, the diffusion length should be assumed to be more than

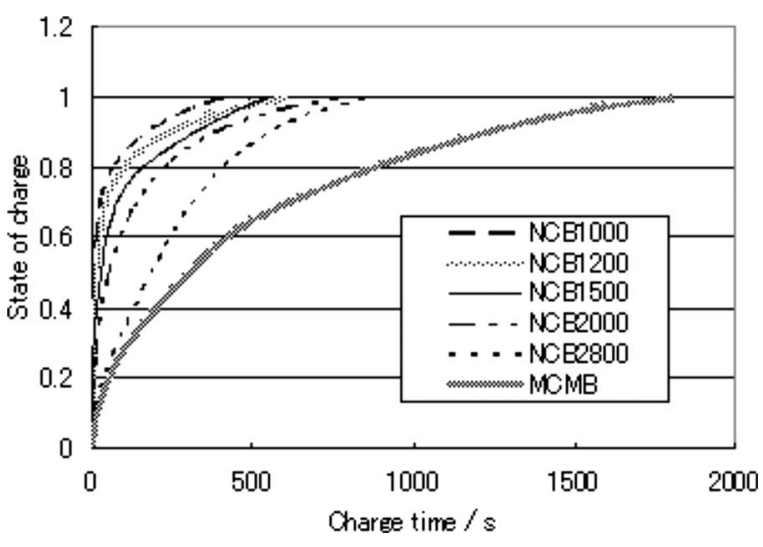

Figure 9. Relationship between potential step charge time (from open-circuit voltage to $0.05 \mathrm{~V}$ ) and state of charge.

$0.1 \mu \mathrm{m}$, and $D_{\mathrm{Li}^{+}}$would thus take on a larger value. Aurbach et al. reported that smaller particles have a smaller $D_{\mathrm{Li}^{+}}{ }^{9}$ This result might be due to the assumption of a shorter diffusion length $l$. Dokko et al. assumed the diameter of the aggregated particle as the diffusion length $l$. In this paper, we used the radius of the CNB as the diffusion length.
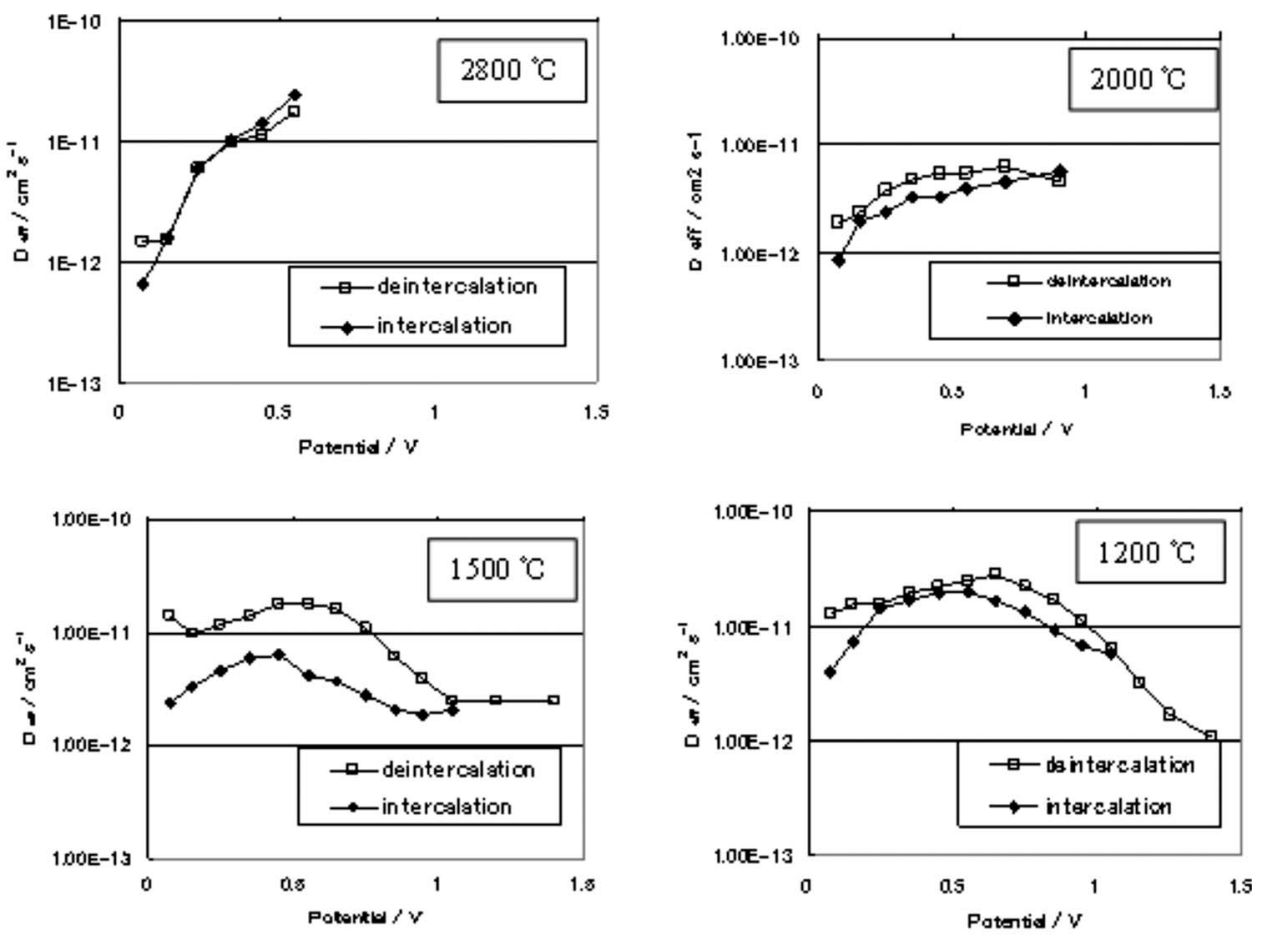

Figure 10. Plots of chemical diffusion coefficients vs potential for $\mathrm{CNB}$.

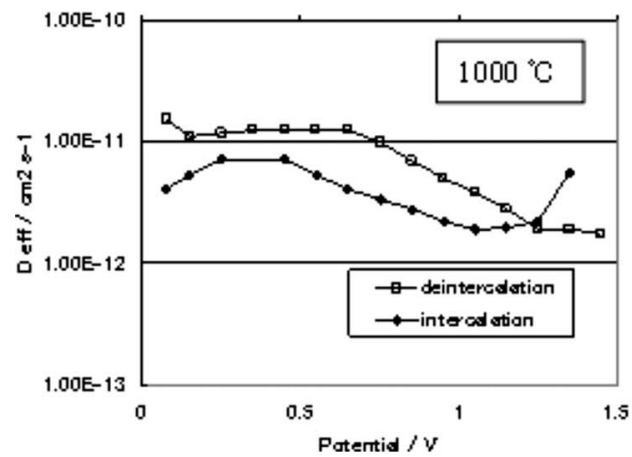


Comparing 2800 and $2000^{\circ} \mathrm{C}$ heat-treated CNBs, $D_{\mathrm{Li}^{+}}$for $2000^{\circ} \mathrm{C}$ was larger below $0.2 \mathrm{~V}$ and smaller above $0.2 \mathrm{~V}$. The $D_{\mathrm{Li}^{+}}$ difference in the direction of intercalation/deintercalation was observed in 1500,1200 , and $1000^{\circ} \mathrm{C}$ heat-treated CNBs. The difference in direction was not observed at $2800^{\circ} \mathrm{C}$. For the $2800^{\circ} \mathrm{C}$ case, $D_{\mathrm{Li}^{+}}$is controlled by the lithium-ion diffusion in the CNB. The diffusion coefficient $D_{\mathrm{Li}^{+}}$does not differ depending on the direction of intercalation/deintercalation ${ }^{1,17}$ if the rate-determining step is the lithium-ion diffusion within the CNB. We think that for the 1500 , 1200 , and $1000^{\circ} \mathrm{C}$ heat-treated $\mathrm{CNBs}$, control is via interfacial lithium-ion transfer.

Below $1500^{\circ} \mathrm{C}$ heat-treatments, there are peaks of $D_{\mathrm{Li}^{+}}$between the 0.3 and $0.7 \mathrm{~V}$ range. The $D_{\mathrm{Li}^{+}}$of the intercalation direction at $1200^{\circ} \mathrm{C}$ is larger than that for other CNBs. The high value of $D_{\mathrm{Li}^{+}}$in the $1200{ }^{\circ} \mathrm{C}$ heat-treated $\mathrm{CNB}$ is consistent with the results of $\mathrm{CV}$, charge/discharge, and potential step.

\section{Conclusion}

We investigated the electrochemical characteristics of CNB by the microelectrode method. From the results of $\mathrm{CV}$, below $1500^{\circ} \mathrm{C}$ an anodic current peak was observed at around $1 \mathrm{~V}$ and above $2000^{\circ} \mathrm{C}$ the anodic current peak was below $0.5 \mathrm{~V}$. At a high sweep rate, the capacity in the $2800^{\circ} \mathrm{C}$ heat-treated CNB and MCMB was much lower than that below $1500^{\circ} \mathrm{C}$.

The $1200^{\circ} \mathrm{C}$ heat-treated CNB showed the highest discharge capacity at a high rate measured by constant current charge/discharge. It was possible to discharge above $1000 \mathrm{C}$.

The discharge time was measured by the potential step method. The discharge time was longest for the $2800^{\circ} \mathrm{C}$ heat-treated CNB. The discharge time for MCMB was much shorter than for the $2800^{\circ} \mathrm{C}$ heat-treated $\mathrm{CNB}$. The charge time was ordered by the temperature of heat-treatment. A higher temperature showed a longer charge time. MCMB was much longer than the $2800^{\circ} \mathrm{C}$ heat-treated CNB. This result is opposite to discharge.
Lithium-ion diffusion coefficient in CNB was measured by PITT The $1200^{\circ} \mathrm{C}$ heat-treated $\mathrm{CNB}$ showed the highest current density In the $2800^{\circ} \mathrm{C}$ heat-treated $\mathrm{CNB}$, there is little difference in both directions, intercalation/deintercalation, as compared with other temperatures. The intercalation direction dependence was large below the $1500^{\circ} \mathrm{C}$ heat-treated CNB. The potential of the maximum value of the diffusion coefficient was different for the direction of intercalation/deintercalation.

TDK Corporation assisted in meeting the publication costs of this article.

\section{References}

1. M. D. Levi and D. Aurbach, J. Phys. Chem. B, 101, 4641 (1997).

2. M. D. Levi and D. Aurbach, J. Electroanal. Chem., 421, 79 (1997).

3. M. D. Levi, E. Markevich, and D. Aurbach, J. Phys. Chem. B, 109, 7420 (2005).

4. A. Funabiki, M. Inaba, T. Abe, and Z. Ogumi, J. Electrochem. Soc., 146, 2443 (1999).

5. A. Funabiki, M. Inaba, T. Abe, and Z. Ogumi, Electrochim. Acta, 45, 865 (1999).

6. B. Markovsky, M. D. Levi, and D. Aurbach, Electrochim. Acta, 43, 2284 (1998).

7. B. Markovsky, M. D. Levi, and D. Aurbach, Electrochim. Acta, 43, 2287 (1998).

8. H. Wang, T. Abe, S. Maruyama, Y. Iriyama, Z. Ogumi, and K. Yoshikawa, Adv. Mater. (Weinheim, Ger.), 17, 2857 (2005).

9. K. Dokko, M. Mohamedi, Y. Fujita, T. Itoh, M. Nishizawa, M. Umeda, and I. Uchida, J. Electrochem. Soc., 148, A422 (2001).

10. T. Nishina, H. Ura, and I. Uchida, J. Electrochem. Soc., 144, 1273 (1997).

11. I. Uchida, H. Fujiyoshi, and S. Waki, J. Power Sources, 68, 139 (1997).

12. Y. Yamamoto, T. Tahara, and R. Harada, Japanese Pat. 2003-1803 (2003).

13. J. R. Dahn, A. K. Sleigh, H. Shi, J. N. Reimers, Q. Zhong, and B. M. Way, Electrochim. Acta, 38, 1179 (1993).

14. E. Buiel and J. R. Dahn, Electrochim. Acta, 45, 121 (1999).

15. T. Zheng, W. R. McKinnon, and J. R. Dahn, J. Electrochem. Soc., 143, 2137 (1996).

16. K. Tatsumi, T. Akai, T. Imamura, K. Zaghib, N. Iwashita, S. Higuchi, and Y Sawada, J. Electrochem. Soc., 143, 1923 (1996).

17. J. S. Gnanaraj, M. D. Levi, E. Levi, G. Salitra, D. Aurbach, J. E. Fischer, and A. Claye, J. Electrochem. Soc., 148, A525 (2001).

18. C. J. Wen, B. A. Boukamp, R. A. Huggins, and W. Weppner, J. Electrochem. Soc., 126, 2258 (1979) 